\title{
Flow drilling technology and thread forming - an economical and secure connection in hollow sections and thin-walled components
}

\author{
Roland Heiler* \\ Faculty 2: School of Engineering - Technology and Life, HTW Berlin, 12459 Berlin, Germany
}

\begin{abstract}
Detachable and highly loadable screw connections can only be realized in thin-walled components and in particular hollow profiles with great effort. The flow drilling technology and subsequent thread forming represents an economical and technically interesting manufacturing alternative. With Flow drilling, a bush is generated by a fast-rotating carbide taper mandrel and a high resistant internal thread can be produced in a subsequent manufacturing process. Conventional weld- or rivet nuts can be replaced in many application areas.
\end{abstract}

\section{The challenge}

In many areas of mechanical and plant engineering, aviation and the construction industry, designers and production engineers are confronted with the task of connecting components and structural components. If fixed, non-detachable connections are required, depending on the area of application, the different non-detachable joining technologies are used. In particular, the processes of welding, soldering or gluing are used to achieve a resilient connection. However, what possibilities are there if a detachable connection is required, e.g. so that components or assemblies can be assembled or dismantled on site without great effort? In most cases, conventional bolted connections with bolts (external thread) and nuts (internal thread) are used. With this proven method, the desired elements can be connected and, depending on the requirements, disconnected again. However, the use of conventional screw connections reaches its limits when thin-walled components or hollow sections in particular are to be combined. For thin-walled components such as sheet metal constructions, the use of screw-nut connections is possible, provided that both sides are easily accessible for assembly. Depending on the requirements, different variants of the "screw-nut" versions can be found here. Conventional screws and nuts are often used.

If the two components are to be screwed together directly, however, the simple sheet thickness is not sufficient for the production of a high-strength screw connection, since only a small number of load-bearing threads can be inserted into this. The screw connection is quickly overtightened during assembly and can no longer fulfil the holding function. In order to achieve only sufficient pull-out or assembly strength, the sheet thickness would

* Corresponding author: Roland.Heiler@htw-berlin.de 
have to be significantly increased so that at least the thread length of a comparable nut can be achieved. The often higher strength properties of the nuts compared to the existing base material of the components have not yet been taken into account. Alternatives are often welding nuts, where the nut is connected to the rear side of the sheet metal component to be assembled via a welded joint and the components are then assembled by using the bolts from the easily accessible front. Alternatively, insert nuts can be used. These are pressed into the sheet metal component from the back before assembly, the nut is connected to the sheet metal by plastic deformation or by punching in shaped elements which are located on the press-in nut and are intended to prevent twisting during assembly of the bolt. These should also prevent loosening of the insert nut before mounting the bolt. If only low loads are to be expected or if no high-strength screw connections are required, conventional sheet metal screws or sheet metal nuts can be used. When using sheet metal screws, multiple disconnecting and connecting is only possible to a very limited extent. A failure of the thread profile in the thin-walled component is to be expected or observed. Increased or improper torques during assembly can also lead to overtightening of the screw connection, which can lead to complete failure of the assembly. When hollow sections are used, the number of available mounting elements is even smaller, as they are only accessible from the front. For such applications, there are usually two mounting options. Either the material thickness of the hollow profile is increased to such an extent that a sufficient number of load-bearing threads can be inserted into the existing wall, or blind rivet nuts are used. Increasing the wall thickness of the hollow profile increases the material costs and the component weight accordingly. This method represents a truly economic solution only to a very limited extent. When blind rivet nuts are used, they are inserted into the hollow profile from the front and then clamped to the hollow profile using blind riveting pliers. Depending on the component and assembly requirements, it is also possible to clamp the blind rivet nut with the hollow profile together with the screw assembly. Different profile versions of the blind rivet nuts are also available to reduce the risk of the blind rivet nut turning during assembly. However, the application requires the insertion of corresponding opening contours into the hollow profile. The mentioned traditional joining methods are material-, time- and cost-intensive. The load-bearing capacity of the detachable connection is sometimes very limited and unintentional loosening of the weld nut, press-fit nut or rivet nut cannot be totally avoided. For thin-walled components and in particular for hollow profiles, the flow drill technology is an economical alternative for producing a sheet metal pull-through and subsequent thread forming! 


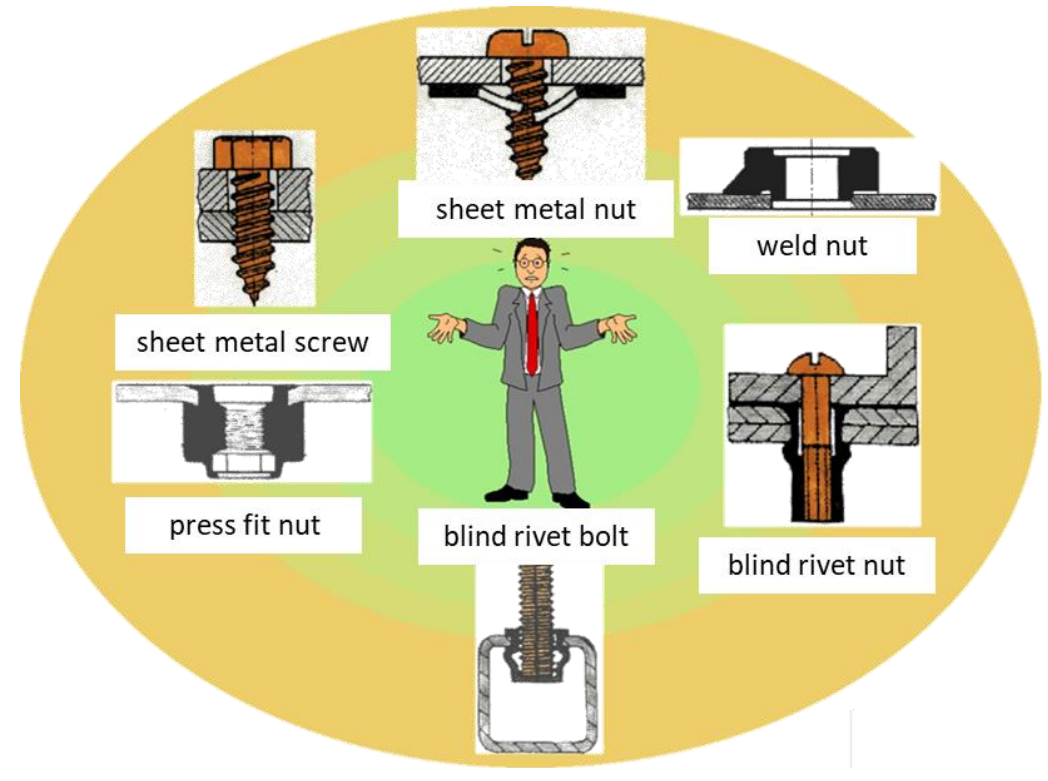

Fig. 1. Alternative joining methods for sheet metal and thin-walled hollow sections $[1,2]$

\section{Flow drill technology - the process}

In the flow drilling technology (the process is also known as flow punch forming, friction drilling, thermal friction drilling), a fast-rotating carbide taper mandrel is pressed onto the thin-walled component or sheet metal under axial force or with a feed movement. The tool (called flow drill, friction drill or thermal friction drill) is positioned on the surface by the grounded centring point of the flow drill and enables the precise insertion of the later pullthrough. In the initial phase of the flow forming process, the material is initially displaced upwards against the feed direction of the tool. The material offers the greatest resistance to deformation and the axial forces are highest at this moment. As the feed motion increases and the friction between the rapidly rotating tool and the stationary workpiece increases, the workpiece heats up very quickly in the contact zone. A further axial infeed of the taper mandrel results in a rising friction surface and the material is heated up very strongly. Depending on the material and the resulting heat conduction, temperatures of up to approximately $900^{\circ} \mathrm{C}$ can occur [1]. This greatly reduces the yield stress of the material to be formed, and the process moves from the initial cold forming stage to the semi-hot to hot forming stage. The yield stresses of the metallic materials are so strongly reduced in the contact area that the taper mandrel can be pressed into the material with considerably less force. The yield stress in the area of hot forming is only about $10-20 \%$ of the yield stress at room temperature [3]. The displaced material flows more and more in the feed direction during this phase of forming process and due to the initially conical tool. Gradually a bushing forms on the underside of the sheet. As soon as the taper mandrel pierces the material on the underside, the axial force continues to decrease noticeably. At the same time, the material is increasingly displaced in the feed direction. With the further feed movement of the flow drill, the pull-through is formed according to the geometry of the tool. After reaching the maximum drilling depth, the tool is returned to its starting position without dwell time in rapid traverse. This prevents the flow drill from jamming when the workpiece temperature is reduced. In the final phase of the process, the upwardly displaced material is formed into either a collar or an annular geometry. The material displaced 
upwards can also be machined by drilling or milling cutters ground onto the flow former. In this case, a flat surface is created on the upper side of the component, which can also be used as a sealing surface. In the case of curved surfaces or tubular components, a flat coil system can also be realized. The material distribution against the feed direction and in the feed direction of the tool depends not only on the tool diameter used but also on the sheet thickness to be machined. With increasing sheet thickness, the proportion of material displaced upwards increases. In a first approximation, the material distribution is approx. $1 / 3$ opposite and approx. $2 / 3$ in feed direction.
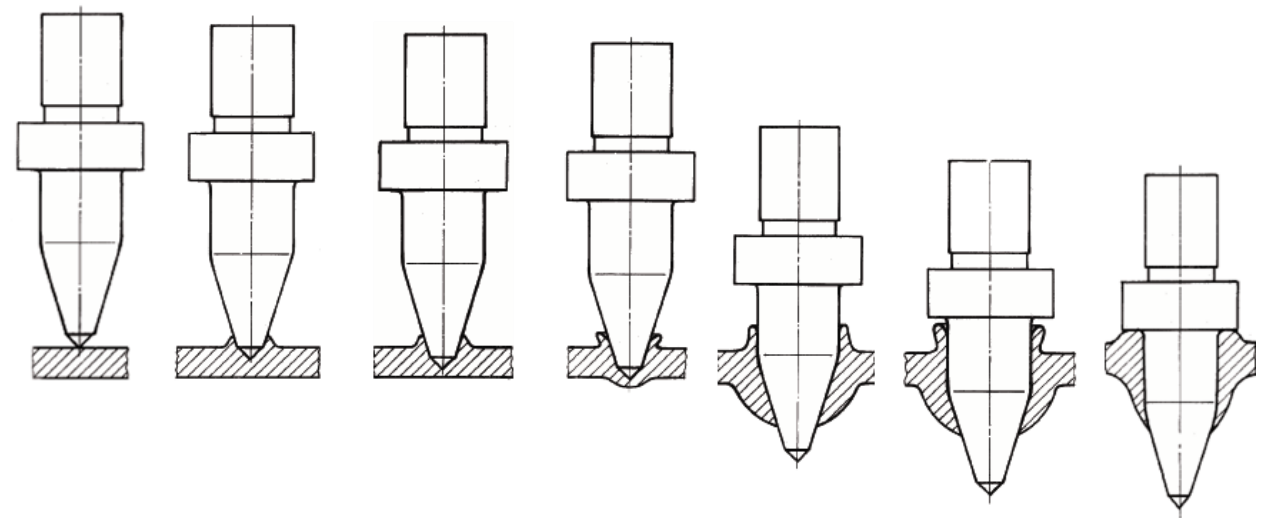

Fig. 2. Phases of the bush formation using the flow drilling technology [1, 2]

Flow drilling produces comparatively high axial forces, especially in the first process phase. The following diagram shows the axial forces as a function of the tool diameter when machining a conventional structural steel S235 (wall thickness $2 \mathrm{~mm}$ ). The axial force increases significantly with a increasing tool diameter. The bandwidth of the maximum axial force is influenced by the available or set tool speed and feed speed of the flow drill. In principle, the axial force is reduced with increasing speed and reduced feed rate of the tool. However, this leads to increased production times and can lead to overheating of the carbide and a reduced tool life.

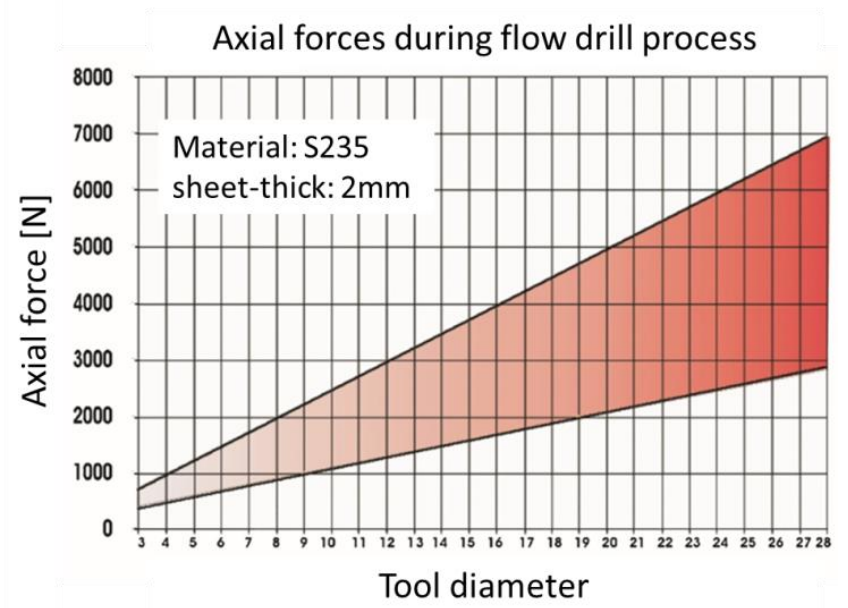

Fig.3. Axial forces as a function of tool diameter during flow drill S235 sheet metal [4] 
Flow drilling can be used in production on power- or distance-bound machine tools with rotating main spindles. As the process is often used in combination with other machining processes, it is increasingly used on CNC machine tools. Smaller dimensions up to a tool diameter of approx. $10.9 \mathrm{~mm}$ can also be inserted manually on conventional column drilling machines. This means that applications in the conventional workshop area are also possible. When used on CNC-controlled machine tools or machining centers, the feed rate of the flow drill can be adapted to the individual forming phases. At the beginning a low feed rate is used (e.g. tool diameter $7.3 \mathrm{~mm}$ for M8 with $\mathrm{v}_{\mathrm{f}}=$ approx. $100 \mathrm{~mm} / \mathrm{min}$ ). With increasing feed travel, the axial feed speed can be increased step by step, when piercing the underside of the sheet metal to $\mathrm{v}_{\mathrm{f}}=500 \mathrm{~mm} / \mathrm{min}$. If the material displaced upwards is machined, the feed speed can be further increased in this final process phase $\left(\mathrm{v}_{\mathrm{f}}=\right.$ approx. $\left.1.000 \mathrm{~mm} / \mathrm{min}\right)$. If the material is to be pressed into a collar, the feed values should be reduced in this phase to prevent unwanted deformation of the upper side of the sheet. Adapting the feed rate results in a significant reduction of the production time in comparison to a constant feed, since the feed rate can be optimally adapted to the process [1]. The speed of the spindle usually remains constant during the forming process, since a variable speed control of the main spindle would increase the production time due to the inertia of the driven elements. The required speeds for flow drilling depend on the material to be machined and the sheet thickness used. Machining conventional structural steel S235 with a sheet-thick of aprox. $2,0 \mathrm{~mm}$ the spindle rotation starts for small tools with diameter $3,00 \mathrm{~mm}$ in the range of 3.000RPM and should be reduced up to 1.200RPM for tool diameters in the range of $18,00 \mathrm{~mm}$. For thicker sheets over $4.0 \mathrm{~mm}$, the speeds should be reduced by approx. 10-20\% to prevent overheating of the tool, increased thermal wear or tool breakage [2]. If the sheet metal is very thin (less than $2.0 \mathrm{~mm}$ ), it may be necessary to support the components to prevent the workpiece from deflecting.

\section{Flow drill tool and design variants}

Flow drilling tools are made of a tungsten carbide that is as heat resistant as possible. Due to the very high forming temperatures, both the component and the tool are annealed during machining, high speed steels cannot be used as tool materials. To increase the forming temperature, the tools are ground to a polygonal cross-section. The polygonal cross section, especially in the conical forming area, allows not only the pure frictional heat but also an increase in the forming temperature through additional forming or rolling work. With the help of the polygon profile, the material is additionally "kneaded" and heated.

The design of the flow drill primarily depends on the desired design of the bush or on the function to be achieved on the component. Two fundamentally different tool variants are available. In the first version, the material displaced upwards is formed into a collar. Flow drills with ground collar are used for this purpose. The collar wraps the material around or compresses the material directly against the component surface, comparable to a washer in conventional bolted connections. If a flat bearing surface on the upper side of the component is desired, flow drills with ground drilling or milling blades are used.

In addition to these two basic designs, the length of the cylindrical part is also of decisive importance. If cylindrical passages are required, tools with a long cylindrical part are used. This allows, depending on the sheet thickness, a cylindrical shape of the bush. This tool design is usually referred to as the "long tool design". If, on the other hand, threads are to be inserted into the bush, shorter tool designs have proved their worth. The use of a flow drill with a shortened cylindrical part results in slightly conical sheet metal bushes. These tools are usually referred to as the "short tool design". These are suitable as bushes for subsequent thread forming. The tapered bush provides greater resistance in the radial direction to the forming of the thread flanks of the thread former. This "quasi- 
preload" of the bush allows a better shaping of the thread flanks and higher axial pull-out forces of the screw connection can be achieved.

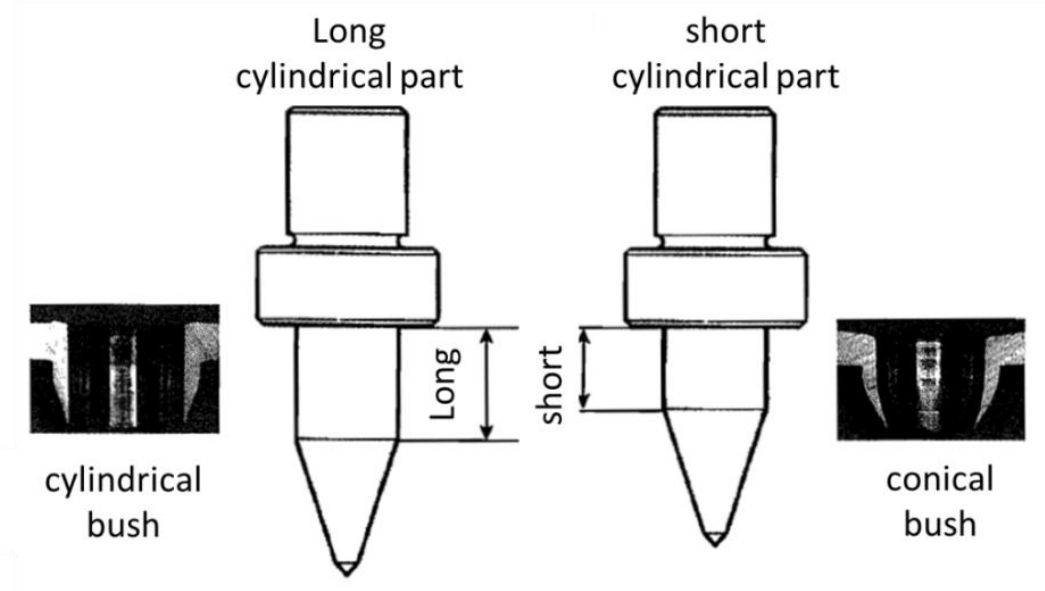

Fig. 4. The tool design determines the shape of the cylindrical part of the formed bush [1]

\section{Thread forming in sheet metal bushes}

After the sheet metal bush has been inserted into the component, a pull-out-proof thread can be inserted into the sheet metal bush in a subsequent manufacturing step. In contrast to conventional internal thread production, in which the thread is usually machined by tapping or thread cutting, the internal threads should be produced in flow drilled bushes by using the thread forming technology.

In thread forming, the tool, the so-called thread former, is screwed into the sheet metal at room temperature in a helical movement. The thread former displaces the material, which flows axially and radially along the flanks of the tool, forming the characteristic, clawshaped open thread profile. Since this process is a forming process, the inner material fibres are more likely to be deflected and less severed. The formed thread flanks have a higher strength than the base material due to the strain hardening of the material. Together with the favourable material structure and the thread flanks also formed in the lower area of the bush, pull-out-resistant threaded bushes can also be produced in thin-walled sheet metal or hollow sections.

The diameter of the flow drill (cylindrical shaped part) is adapted to the subsequent thread forming process. In contrast to conventional thread forming in solid components, the tool diameter is slightly smaller, depending on the thread design by approx. $1 / 10 \mathrm{~mm}$. This results in better shaping of the thread flanks in thin-walled sheet metal bush. Overforming of the thread and the resulting failure of the thread former, as can occur with conventional thread forming into solid components, is prevented by the greater flexibility or elastic expansion of the bush during the forming process.

Thread formers, similar to flow drills, are also designed with a polygonal cross-section profile. The individual pressing lubes or forming edges allow the material to be formed. For thread forming in bushes, hard material-coated thread formers made of high speed steel (HSS-E/HSS-Co) or solid carbide (SC) are usually used. Thread formers made of HSSE/HSS-Co or powder metallurgically produced high speed steel (HSS-E-PM/HSS-Co-PM) often have a higher process reliability against tool breakage than solid carbide thread formers. Solid Carbide taps are rather unsuitable for unstable production conditions, unstable components or on older machine tools due to their significantly reduced fracture 
toughness compared to HSS-E/HSS-Co and can only be used reliably under real stable production conditions. The threaded bushes produced by flow drilling and cold thread forming are highly pull-out resistant. The characteristic values given in table $1[1,5]$.

Table 1. Pull-out force depending on thread size for different sheet thicknesses

\begin{tabular}{|c|c|c|c|c|c|c|c|c|}
\hline \multirow{2}{*}{$\begin{array}{c}\text { sheet } \\
\text { metal }\end{array}$} & \multicolumn{7}{|c|}{ pull out force in [kN] in material S235 } \\
\cline { 2 - 10 } & M4 & M5 & M6 & M8 & M10 & M12 & M16 & M20 \\
\hline 1.0 & 6 & 10 & & & & & & \\
\hline 1.5 & & 13 & 16 & & & & & \\
\hline 2.0 & 9 & 15 & 17 & 27 & & & & \\
\hline 3.0 & & & 24 & 42 & 53 & 72 & 97 & 142 \\
\hline 4.0 & & & & 45 & 72 & 91 & 105 & 162 \\
\hline 5.0 & & & & & & 101 & & $>200$ \\
\hline
\end{tabular}

\section{Application examples for flow drilling and thread forming}

Flow drilling in combination with subsequent thread forming opens up a wide range of application possibilities. Conventional fasteners such as welded nuts, press-in nuts or blind rivet nuts can be replaced. This saves production steps, production time and the resulting production costs, but can also increase the process reliability of the components. In addition to this main application of the process, there are also other possible applications. The bush can be used for the use of self-forming screws. The screw is screwed directly into the bush and forms its own thread. The pure, cylindrical sheet metal bush can also be used directly for the production of a bearing, soldering, plug-in or welding joint. Even the production of a sealing surface is possible. Investigations have shown that flow drilling also makes it possible to introduce passages into vertical edges and sections. This innovative production step opens up further application possibilities for the manufacturing process [5].

\section{Summary}

Flow drilling in combination with the subsequent thread forming enables the production of pull-out resistant threaded bushes in thin-walled components and hollow profiles. The process can be used on both, conventional and $\mathrm{CNC}$ machine tools and represents an economical alternative to conventional joining processes such as welding, press-in or blind rivet nuts. Further applications result from the simple bush without internal thread in the area of bearing or contracting points for soldering or welding.

The author would like to thank Dipl.Wirt.Ing. (FH) Sven Rautenberg of FLOWDRILL Germany $\mathrm{GmbH}$ for his kind support in carrying out experiments on flow drilling and thread forming.

\section{References}

1. R. Heiler 1999: Fließlochformen und Gewindefurchen auf NC gesteuerten Werkzeugmaschinen. Fortschr.-Ber. VDI Reihe 2, Nr.526, Düsseldorf, VDI-Verlag 1999

2. S. Rautenberg: FLOWDRILL Process and applications, documents for the lecture, FH Mannheim 
3. R. Herbertz, H. Hermanns and R. Labs 2015: Massivumformung kurz und bündig. ISBN 978-3-928726-32-0

4. FLOWDRILL GmbH 2018: Effizient und spanlos verbinden, company brochure Fa. FLOWDRILL

5. T. Engbert 2011 (Dissertation): Fließbohrbearbeitung und Innengewindefertigung an Leichtbaustrukturen (Dortmund: TU Dortmund) 